\title{
Controversias de la movilidad: El caso del Puente sobre el canal Chacao, Archipiélago de Chiloé, sur austral de Chile
}

\author{
Controvérsias de mobilidade: O caso da ponte sobre o \\ Canal de Chacao, Arquipélago de Chiloé, sul do Chile \\ Mobility controversies: The case of the Chacao Bridge, \\ Chiloé archipelago southern Chile
}

\author{
Alejandra Lazo Corvalán [a] [D], Hernán Riquelme Brevis [b] [D], \\ Diego Solsona Cisterna [a] [D], Patricio Anabalón [a] (iD)
}

[a] Universidad de Los Lagos, Osorno, Chile

[b] Universidad Autónoma de Chile, Temuco, Chile

Cómo citar: Lazo Corvalán, A., Riquelme Brevis, H., Solsona Cisterna, D. \& Anabalón, P. (2021). Controversias de la movilidad: El caso del Puente sobre el canal Chacao, Archipiélago de Chiloé, sur austral de Chile. urbe. Revista Brasileira de Gestão Urbana, v.13, e20200172. https://doi.org/10.1590/2175-3369.013.e20200172

\section{Resumen}

Durante las últimas décadas, las prácticas de movilidad de los habitantes de Chiloé se han visto influenciadas por la instalación de diversos tipos de infraestructuras, lo cual tiene una repercusión en múltiples esferas sociales, haciendo de la vida cotidiana isleña un campo en tensión entre lo tradicional y lo moderno. La discusión presentada se enmarca en la controversia en torno a la construcción de un puente que unirá el Continente con el Archipiélago de Chiloé, en el sur austral de Chile, bajo el supuesto que esta infraestructura permitirá a sus habitantes mayor movilidad, conectividad y, en consecuencia, mayor acceso al mundo. En términos metodológicos, se realizó un análisis de prensa que exhibe los principales acontecimientos que implican la construcción del puente, para ello se utiliza la categoría controversias con el objetivo de pensar la movilidad. Dentro de los resultados destaca el rol del puente como detonador de narrativas que ponen en el centro de la vida moderna a la movilidad, la sensación de una hipermovilidad como actividad que debe ser desarrollada por la mayoría de la población, las divergencias discursivas respecto a la comprensión de la movilidad y la relevancia de las controversias en las ciudades.

Palabras clave: Controversias. Infraestructura de la movilidad. Conectividad. Archipiélago. Actor social.

ALC es investigadora, doctora en Geografía y Planificación Territorial, e-mail: alejandra.lazo@ulagos.cl

HRB es investigador (IR FONDECYT 3200682), doctor en Ciencias Sociales, e-mail: h.riquelmebrevis@gmail.com

DSC es investigador, magíster en Investigación y Desarrollo, e-mail: diego.solsona@umag.cl

PA es investigador, magíster en Desarrollo Humano Local y Regional, e-mail: patricioanabalonb@gmail.com 


\section{Resumo}

Nas últimas décadas, as práticas de mobilidade dos habitantes de Chiloéforam influenciadas pela instalação de vários tipos de infraestrutura, o que tem impacto nas esferas, fazendo da vida cotidiana da ilha um campo de tensão entre o tradicional e o moderno. A discussão apresentada neste artigo é parte da polêmica em torno da construção de uma ponte que ligará o continente ao Arquipélago de Chiloé, no sul do Chile, sob o pressuposto de que essa infraestrutura permitirá aos seus habitantes maior mobilidade, conectividade e, consequentemente, maior acesso ao mundo. Em termos metodológicos, foi realizada uma análise de imprensa mostrando os principais eventos envolvendo a construção da ponte, utilizando a categoria das controvérsias para pensar a mobilidade. Entre os resultados, destacam-se o papel da ponte como detonador de narrativas que colocam a mobilidade no centro da vida moderna, a sensação de hipermobilidade como atividade que deve ser desenvolvida pela maioria da população, as divergências discursivas quanto à compreensão da mobilidade entre os diversos atores sociais envolvidos no problema e a relevância das controvérsias nas cidades.

Palavras-chave: Disputas. Infraestrutura de mobilidade. Conectividade, Arquipélago. Ator social.

\section{Abstract}

In recent decades, the mobility practices of the inhabitants of Chiloé have been influenced by the installation of various types of infrastructure, which has an impact on the socio-economic, cultural and political spheres, making island daily life a field in tension between the traditional and the modern. The discussion presented in this article is based on the controversy regarding the construction of a bridge connecting the continent with the Chiloe archipelago in the south of Chile, under the assumption that the infrastructure will grant more "mobility", connectivity and better access to the world. In the last few decades, the mobility practices of Chiloé inhabitants have been influenced by the complex situation caused by the construction of the bridge. This influences different socioeconomic, cultural and political areas, creating tension between traditional and modern daily life. Methodologically, a press analysis was carried out, including the main events involving the construction of the bridge. For this reason, the category of controversies is used when thinking about mobility. Among the main results, the role of the bridge as a trigger for narratives that place mobility in the middle of modern life, the sense of hypermobility as an activity that must be followed by the majority of the population, the discursive divergence regarding the understanding of mobility among the diverse social actors that are involved in the problem, and the importance of controversies in the understanding of social conflicts in the cities.

Keywords: Controversies. Mobility infrastructure. Connectivity. Archipelago. Social actor.

\section{Introducción}

En términos generales, el concepto controversia procede de estudios relacionados con la Actor Network Theory (Latour, 2002, Latour, 2005, Callon, 1995), como también con la No Representational Theory (Thrift, 2004, 2007, Vannini, 2015, 2011), ambos constituyen dispositivos teórico-metodológicos novedosos e incipientes para rastrear lo social y describir las conexiones entre agentes. En efecto, se plantea que el estudio conceptual y práctico de las controversias no puede estar separado de agencias diversas, sean estas humanas y no humanas.

Como lo han señalado diferentes autores (Latour, 1987, Chateauraynaud, \& Torny, 1999, Callon et al., 2001), el potencial metodológico y analítico de las controversias refiere a cómo los actores negocian y coconstruyen nociones que exceden las instituciones científicas (Latour, 2002). Las controversias "empiezan cuando los actores descubren que no pueden ignorarse mutuamente y terminan cuando los actores logran un compromiso sólido para vivir juntos" (Venturini, 2009, p. 261), contraponiéndose al etnocentrismo ontológico del saber experto, tecno- ciencia, o saber producido entre comunidades de expertos (Latour, 1987). 
Advertimos sobre la utilización del concepto controversia por sobre el concepto conflicto- y su relevancia en la promoción de sociedades democráticas-, ya que consideramos que las controversias también pueden ser leídas en clave conflicto social pero con matices epistemológicos, donde categorías como género, clase o etnia tensionan y permiten observar fenómenos y problemáticas sociales desde lógicas de grupos opuestos que interactúan a partir de concepciones de mundo e intereses disímiles.

La teoría de los conflictos sociales (Dahrendorf, 1959, 2007) asoma como un enfoque central en lo que respecta a una supuesta superación de la lucha de clases como motor de la sociedad. Para Dahrendorf (1971), los sectores dominantes deben rearticular sus ideas constantemente con el objetivo de desactivar las ansias de transformación social de los sectores dominados. A su vez, el poder es fundamental en lo que respecta a la generación de conflictos sociales, donde la autoridad está dicotómicamente enfrentada a grupos sociales, lo que repercute en la reproducción del conflicto social. Al entender ello, optamos por el concepto controversia -y su potencialidad metodológica como forma y parte de los conflictos- por sobre una lectura en base al conflicto social, ya que al referir las controversias se abren diversas discusiones respecto a las interacciones humanas, actores sociales, objetos y territorios estudiados en la presente investigación.

La discusión que presentamos se enmarca en la controversia en torno a la construcción del puente que une el continente con el Archipiélago de Chiloé bajo el supuesto que esta infraestructura permitirá a sus habitantes mayor movilidad, conectividad y, en consecuencia, mayor acceso al mundo occidental. De esta manera, analizamos la infraestructura de la movilidad, representada en el puente, a partir del concepto de controversia y su relación con diversos actores, instituciones y hechos sociales que han organizado el derrotero histórico de la implementación del puente de Chacao.

El artículo se divide en cinco apartados. En un primer momento caracterizamos y definimos teóricamente lo que es una controversia, principalmente desde los aportes del científico social Bruno Latour. En segundo lugar, abordamos la movilidad como un paradigma de la sobre- modernidad que vendría a significar ser libre o estar conectado en la ciudad (Augé, 2000). En un tercer momento, nos referimos a los dispositivos metodológicos utilizados en este trabajo, y que dan cuenta de la controversia estudiada como referente empírico. En cuarto lugar, presentamos resultados en base a un análisis de prensa, donde caracterizamos al Archipiélago de Chiloé, basándonos en algunas constelaciones de la movilidad imperantes en el territorio, para posteriormente referirnos explícitamente a la controversia en torno a la construcción del puente de Chacao, enfatizando en las resistencias y contra-experticia de los actores locales que se oponen al proyecto. Finalmente, compartimos algunas reflexiones que dan cuenta que estamos frente a una controversia in continuum, la cual lejos de terminar recién comienza.

\section{¿Qué es una controversia?}

El concepto controversia ha adquirido gran relevancia y visibilidad en el último tiempo, gracias a los planteamientos de Bruno Latour. A partir de la emergencia de Actor Network Theory, Latour comienza a desarrollar las controversias, no como un simple mediador conceptual con potencial explicativo-interpretativo, sino como una herramienta metodológica plausible para abordar la realidad social.

Para Latour (2007), una controversia no es nada más ni nada menos que una "tensión”. En palabras de Venturini, una controversia es: "cada pedacito de la ciencia y la tecnología que aún no está estabilizada, cerrada o en la "caja negra"; no significa que hay un conflicto feroz ni que se ha politizado; lo utilizamos como término general para describir incertidumbre compartida" (2009, p. 3). En este sentido, Latour (2007), recomienda observar y describir las controversias que aparecen como una expresión inequívoca de la realidad social, lo más representativo de la convivencia humana, lograda o fallida. 
En términos más específicos, una controversia incluye situaciones donde discrepan los actores. Las controversias comienzan cuando los actores descubren que no pueden ignorarse y las controversias finalizan cuando los actores logran un compromiso sólido para coexistir.

Considerando estas definiciones parciales de controversias, se infiere, según Latour, algunos elementos básicos que las caracterizan (Latour, 2007, 2005, 2004). Al respecto, Venturini (2009) sostiene:

1. Las controversias no se reducen a incorporar solamente a actores humanos.

2. Las controversias se despliegan a lo social en su forma más dinámica.

3. Son reducción-resistentes.

4. Las controversias son debatidas.

5. Las controversias son conflictos.

Otro acercamiento para comprender qué es una controversia a nivel conceptual es lo que plantean Landström \& Whatmore (2011), quienes afirman que una controversia nos abre al momento de perturbación ontológica en donde las cosas en las que descansamos como partes no examinadas del tejido material de nuestro cotidiano se vuelven difusas. Son los actores quienes despliegan estrategias para extender sus redes y entrar en negociaciones con otros actores en pos de imponer sus definiciones o un determinado orden del mundo. Esto es denominado como proceso de traducción por Latour (1992), o como framing por Callon según indica Jolivet \& Heiskanen (2010 apud Buschmann \& Jacob, 2013).

En relación con estudios empíricos sobre controversias, encontramos algunas investigaciones relevantes sobre el tema. Buschmann \& Jacob (2013) utilizaron el modelo de Latour para analizar el caso Cerro industrial Ventanas en Chile. Para estos autores, la controversia se inicia cuando lo que a simple vista pareciera ser sólo un problema medioambiental se devela como un conflicto en torno a la toma de decisiones sobre un espacio que es habitado por comunidades a las que históricamente se les ha impuesto un modelo de desarrollo basado en el establecimiento de un polo industrial. Contaminación, aglomeraciones industriales, detrimento identitariopaisajístico en los habitantes del cerro ventanas, son algunos de los efectos que promovieron la irrupción de una controversia.

No obstante, para Bijker \& Pinch, "los artefactos tecnológicos son culturalmente construidos e interpretados; en otras palabras, poseen una flexibilidad interpretativa” (1987, p. 51). En este sentido, lo que es progreso para las autoridades y ganancia para los empresarios, se traduce en perdida identitaria, contaminación, efectos en salud y malestar general para otros.

Buschmann \& Jacob (2013) también reconocen que las decisiones iniciales (instalar industrias, construir un puente o un mall) serán el inicio de una cadena de decisiones tendientes a instalar sistemas tecnológicoscientíficos que generan ciertas dependencias, y que representa la matriz primigenia de la cultura neoliberal, donde el consumo se torna principal fuente de deseo de la población (Riquelme et al., 2020). Hughes (1987), afirma que lo más elemental de este tipo de sistemas técnicos a gran escala, proviene de la implicancia de ámbitos políticos, tecnológicos, sociales, económicos y culturales.

Estos autores, destacan también el papel que tiene la prensa para invisibilizar controversias, y cómo la sociedad naturaliza las decisiones que se les imponen en lo cotidiano. Solo las personas más informadas tenderían a reaccionar ante las controversias, usualmente imponiendo recursos judiciales. Los autores concluyen que las controversias frecuentemente tienen su génesis en la toma de decisiones top-down, donde el Estado y las empresas dictaminan bajo sus parámetros el camino de desarrollo para una comunidad, lo cual trae como consecuencia la generación de nuevas problemáticas sociales relacionadas con las asimetrías de cuotas de poder.

En México, Zetin-Rodríguez (2016) analiza una controversia ambiental referida a la instalación de una represa en el Estado de Zacatecas. La autora parte del supuesto teórico de que existen dos posibilidades 
respecto al devenir de una controversia: 1) Quedar en el olvido ante la aparición de nuevos postulados y teorías y 2) Permanecer vigente mientras existan actores interesados en refutar los puntos de vista de los involucrados en la polémica (Latour, 1989, p. 1). Se asume, entonces, que en una controversia "intervienen actores que desarrollan argumentos contradictorios y [...] esos puntos de vista [...] llevan a proponer diferentes versiones del mundo social y natural" (Callon, 1986, p. 198).

En una línea similar, Tironi (2011) realizó un estudio relacionado con el uso de bicicletas en Paris. El autor enfatiza en develar cómo se construyen las infraestructuras urbanas, a propósito del uso de las bicicletas, y cómo esta práctica responde a la convocatoria de construir "ciudades verdes". La controversia se genera a partir de una concesión que entrega la administración de las infraestructuras para el uso de las bicicletas en Paris a una empresa privada, esto genera la resistencia de los usuarios, quienes respondieron principalmente a través de acciones legales.

Experiencias de investigación como las descritas, iluminan respecto a cómo abordar empíricamente una controversia, al mismo tiempo que demuestran el potencial metodológico, técnico y analítico de las controversias para estudiar fenómenos sociales que, a priori, pueden parecer como "conflictos tradicionales" en torno a una decisión política que tiene efectos en las comunidades locales, para así avanzar hacia un tipo de estudios que nos permitan capturar la mayor cantidad de conexiones y asociaciones entre actores, sus discursos y acciones, y sobre todo vislumbrar cómo estas no son "simples posiciones", sino más bien, elementos constitutivos de los hechos que se despliegan, situación que develaremos en nuestro caso empírico de la construcción del puente en el canal de Chacao, Chiloé.

De esta forma, podemos apreciar cómo una controversia tiene diversas lecturas y perspectivas teóricas para ser analizada, no obstante, para los objetivos de la presente investigación adherimos al enfoque de Latour, en cuanto a la controversia y su potencial para observar, reconocer y admitir la existencia de diversos grupos sociales que gravitan y reaccionan de múltiples maneras ante una misma problemática.

\section{Las movilidades como controversias}

En los últimos años emergen diversos enfoques (como el denominado mobility turn) que asignan gran importancia a la noción de movilidad para entender las sociedades actuales. Estas perspectivas aparecen como una crítica a los paradigmas estáticos que dominaron las ciencias sociales, y como un impulso para estudiar la sociedad en términos móviles (Urry, 2000) o líquidos (Bauman, 2003).

Según este nuevo paradigma, lo social no se organizaría más en torno a lo inmóvil (o lo estructural), sino en relación con la circulación, movimientos y flujos de mercancías, tecnologías, objetos, sujetos, imágenes, etc. No obstante, pareciera que la movilidad es una capacidad o categoría que viene dada, es decir, una competencia asignada por naturaleza a los actores o a los territorios y, por lo mismo, un recurso que puede ser usado en dosis variables, según el momento y lugar. Sin embargo, y como lo han enfatizado algunos autores (Latour \& Hermant, 1998; Amín \& Thrift, 2004), es importante interrogarse por las condiciones materiales de la movilidad y por las prácticas descriptivas que la hacen inteligible.

Históricamente, la capacidad de desplazamiento no depende únicamente de nosotros los humanos, sino que obedece y se encuentra distribuida en un entorno tecnológico o sistemas "socio-técnicos". Parafraseando a Hughes (1987), el desplazamiento y la movilidad están constituidos por saberes localizados, empresas, técnicas, materiales, ingenieros, entre otros factores, que articulados hacen finalmente posible el movimiento. De la misma forma, no se debe desconocer que la movilidad acompaña la aparición del ser humano, pero en los tiempos actuales adquiere un papel fundamental producto del desarrollo de la globalización y la tecnología, los cuales han revolucionado espaciotemporalmente las experiencias de movilidad cotidiana de la humanidad. 
Relacionado con lo anterior, sugerimos que las "movilidades desiguales" 1 - entendidas como aquellas experiencias y prácticas de desplazamiento condicionadas por factores socioeconómicos y culturales que agudizan las diferencias sociales entre los ciudadanos - pueden ser principios inspiradores de controversias. Por un lado, los pobres siempre fueron confinados a trasladarse a pie, mientras que las elites utilizaban carruajes con animales de carga (Calonge, 2014). El ser humano, ahora entendido como "calzado y civilizado", configura nuevos tipos de espacios púbicos, siendo la culmine de su proyecto lo que conocemos como ciudad. Caminar las calles de una ciudad, dirá Ingold (2004), es una actividad social, inmanente al movimiento de las personas, paso, marcha, dirección y ritmo, que a su vez es respuesta al movimiento de otros en el entorno inmediato.

Por otro lado, las movilidades, desde su conceptualización, deben ser entendidas según sugiere Cresswell (2010), holísticamente, esto significa poner atención al hecho físico del movimiento (desplazarse de un lugar a otro), a la representación que le da un sentido compartido al movimiento. Cresswell (2010), establece que todas las formas de movilidad tienen una realidad física, que están codificadas cultural y socialmente, y que son experimentadas a través de la práctica. Es importante destacar que estas formas de movilidad (caminar, transporte motorizado, entre otras) y aspectos de las movilidades como movimiento, representación y práctica están impregnados de lo político, es decir, están implicados en la producción de poder y las relaciones de dominación.

Para Calonge (2014), las movilidades permitieron un gran flujo de personas en los albores del capitalismo industrial, creando nuevas rutas de circulación que alteraron la geografía del mundo contemporáneo en función de los intereses del capital. Esto repercute en la sociedad moderna, en las grandes diferencias de movilidad entre las elites que son consideradas más cosmopolitas y móviles que las clases subalternas.

El papel del neoliberalismo en las prácticas de movilidad confiere un eje central a las formas de entender las diferencias, exclusiones y desigualdades a las que se ven enfrentadas los habitantes en sus prácticas cotidianas. En este sentido, la movilidad permite una doble entrada en lo que respecta a la ciudad como espacio de reproducción de conflictos y también como lugar de transformación y apropiación (Lefebvre, 2013).

A pesar de lo mencionado, reconocer la movilidad como un discurso que pretende instalarse a modo de horizonte normativo, requiere de un análisis crítico del concepto y de lo que intenta imponer. Algunos autores afirman que la movilidad como discurso moderno o de la sobremodernidad operaria como sinónimo de libertad, autonomía y conectividad (Tironi, 2011; Augé, 2007), sobre todo en sociedades que desarrollan discursos que empujan a la movilidad humana, abriendo una paradoja respecto al alto número de personas que parecen inmóviles en comparación a las pocas que se desplazan a nivel global (Salazar, 2018).

Lo anterior de igual manera se relaciona con lo planteado por Giddens (1993), quien afirma que en la época de la "Hiper-modernidad" la movilidad tiene la virtud de reducir el anclaje secular de las sociedades humanas en el territorio estable y continuo, así como en los tiempos largos. De manera semejante, Augé (2007) afirma que la distribución de los espacios dentro de un territorio -incluyendo el cómo se conciben las infraestructuras que están dentro de él - concentran desigualdades y exclusiones propias de la idea de movilidad. Al mismo tiempo, emerge el concepto de "no-lugar" el cual hace referencia a instalaciones para la circulación acelerada de personas y bienes, puntos de tránsito y ocupaciones provisionales como vías aéreas, ferroviarias, autopistas, los cuales constituyen espacios "no identitarios", que pueden negar o imposibilitar significaciones colectivas para quienes los habitan.

Se trataría de espacios "no relacionales" al impedir un reconocimiento participativo entre dichos sujetos respecto de la significación establecida, y "no históricos" al fomentar una mínima estabilidad en los referentes

\footnotetext{
1 El año 2014, la Universidad de Chile desarrolló la Conferencia Internacional de Movilidades Desiguales, instancia que se transformó en un hito respecto a la discusión nacional sobre la movilidad para comprender, principalmente desde lo metropolitano, los accesos a personas, lugares y actividades.
} 
espacio-temporales que son comunes a todos (Lange-Valdés, 2011), ideas que pueden explicar, en nuestro caso, la instalación de un puente que conecta al archipiélago con el continente.

Por todo lo mencionado, la movilidad con enfoque en las controversias conlleva considerar la diversidad de posiciones que mantienen los agentes y grupos sociales respecto a una misma problemática, abriendo la posibilidad de observar los discursos, intereses y prácticas que implican la transformación de los entornos y cómo ello influye en la calidad de vida de la población.

\section{Metodología de estudio}

En términos metodológicos, los estudios en controversias se basan principalmente en un rastreo de agentes, hitos y discursos que revelan las particularidades de una controversia (Latour, 2007). Para el caso específico de la controversia sobre la construcción del puente en el Canal de Chacao, hemos utilizado técnicas como el análisis de prensa para construir una cronología de la controversia con la finalidad de develar los discursos de los diferentes agentes involucrados, identificando sus intereses y visiones de mundo.

Por una parte, sistematizamos y organizamos hitos relevantes en el diseño del puente. El material escogido está conformado por archivos que recogen el periodo 1990-2019 con el objetivo de analizar los principales acontecimientos y discursos que están involucrados en la planificación, diseño, ejecución, detención y proyección de la construcción del puente.

Por otra parte, confeccionamos cartografías de las controversias, la cuales develan la densidad de actores, discursos e intereses involucrados. Las cartografías fueron diseñadas a través de la codificación mediante el uso del programa ATLAS.ti, con el objetivo de identificar y ensamblar los actores involucrados en ejes temáticos implicados en el puente como objeto que trasciende su papel de infraestructura de la movilidad. Ambas técnicas de investigación fueron contrastadas con fuentes secundarias, sobre todo de estudios realizados por el Centro de Estudios Sociales de Chiloé (CESCH) y algunos artículos de prensa (periódicos). La Tabla 1 entrega las dimensiones que fueron consideradas en la investigación.

Tabla 1. Dimensiones metodológicas analíticas y discursivas

\begin{tabular}{ll}
\hline $\begin{array}{l}\text { 1. Líneas de tiempo de la infraestructura de la } \\
\text { movilidad: El puente como ícono de la } \\
\text { modernidad }\end{array}$ & $\begin{array}{l}\text { Las transformaciones espaciotemporales de la infraestructura de la } \\
\text { movilidad son representadas en objetos que sintetizan diversas } \\
\text { acciones políticas y sociales, tornándose el puente un ícono de la } \\
\text { representación de movilidad en Chiloé. }\end{array}$ \\
$\begin{array}{ll}\text { 2. Cartografías de actores en controversia: } \\
\text { divergencias en las formas de comprender la } \\
\text { movilidad }\end{array}$ & $\begin{array}{l}\text { Los múltiples intereses creados en la construcción del puente } \\
\text { involucran antagonismos entre los actores que se movilizan de } \\
\text { manera asimétrica en pos de sus beneficios personales. }\end{array}$ \\
$\begin{array}{ll}\text { 3. Rasgos distintivos de la controversia } & \text { Las controversias son cambiantes y requieren de diversos actores } \\
& \text { sociales, en este sentido existen factores sociales indicados como } \\
\text { negativos y positivos en la construcción del puente. }\end{array}$
\end{tabular}

Fuente: Elaboración propia (2020).

\section{Resultados y discusión}

Desde el año 2012 y posterior al discurso presidencial del 21 de mayo (El Mostrador Diario, 2012), se ha venido materializando en este archipiélago un discurso sobre el proyecto de construcción del puente en el canal de Chacao. Un proyecto controversial que se fijó como un moderno conjunto socio-técnico de la movilidad. La 
idea de construir un puente sobre el canal de Chacao es un proyecto de larga data y que incluso encuentra sus primeras referencias ya en la década de los sesenta.

De acuerdo con Bravo (2004), los principales argumentos utilizados desde ese entonces eran la modernización definitiva de una zona considerada como deprimida, y acabar con los problemas de la travesía marítima entre Pargua y Chacao.

Recientemente, entre fines del año 2019 y febrero del 2020, se produjo el último conflicto conocido en la historia de la construcción del puente, la empresa Coreana Hyundai acusa al Ministerio de Obras Públicas (MOP) de no reconocer "sobrecostos" en las obras. Por su parte, el MOP aseguraba que no inyectaría más recursos de los que ya estaban comprometidos en los contratos firmados.

Desde sus orígenes este proyecto ha sido controversial dado los altos costos de inversión. Incluso, los criterios técnicos bajo los cuales se justifica el actual proyecto han sido cuestionados en una reciente tesis de investigación desarrollada por Navarro (2014), quien evidencia una serie de errores en el cálculo de la demanda, mostrando que la factibilidad del puente no se alcanzará hasta el año 2029. Por otro lado, el puente es resistido por diversos sectores de la isla de Chiloé, los que ponen en duda los supuestos beneficios sociales y económicos que traerá su construcción, además de enfatizar en los efectos nocivos que implicaría un puente para un territorio insular de particulares características identitarias, culturales y sociales.

En efecto, en los contextos archipelágicos convive al mismo tiempo una lógica de encierro y apertura en la que una parte de la identidad isleña vive arraigada a sus tradiciones, aislamiento, cultura e historia, pero al mismo tiempo una isla se encuentra conectada al mundo a través del comercio, migración, turismo e importaciones bióticas, culturales y materiales (Anabalon, 2018). Por lo mencionado, la Tabla 2 presenta los principales acontecimientos que han implicado las controversias en torno al puente sobre el canal de Chacao.

Tabla 2 - Controversia en torno al proyecto de construcción del Puente Chacao

\begin{tabular}{|c|c|c|c|}
\hline Hitos & Actividades & Actores involucrados & Año \\
\hline \multirow{5}{*}{$\begin{array}{l}\text { La construcción del } \\
\text { Puente de Chacao } \\
\text { como proyecto de } \\
\text { desarrollo del Estado } \\
\text { Chileno }\end{array}$} & $\begin{array}{l}\text { Se propone la idea de la construcción del } \\
\text { puente, se realiza estudio de factibilidad. }\end{array}$ & $\begin{array}{l}\text { Diputado Félix Garay y } \\
\text { Parlamento Chileno }\end{array}$ & 1968 \\
\hline & $\begin{array}{l}\text { Paralización del Proyecto producto del Golpe } \\
\text { de Estado }\end{array}$ & Junta militar & 1973 \\
\hline & $\begin{array}{l}\text { Se convoca a postular a la inscripción de } \\
\text { precalificación en la licitación de los estudios } \\
\text { de ingeniería del puente }\end{array}$ & $\begin{array}{l}\text { Ministerio de Obras Públicas } \\
\text { (MOP) }\end{array}$ & 1997 \\
\hline & $\begin{array}{l}\text { Se retoma la idea del Puente en el contexto de } \\
\text { un "Proyecto Bicentenario" }\end{array}$ & $\begin{array}{l}\text { Presidente Ricardo Lagos } \\
\text { (Gobierno de la Concertación) }\end{array}$ & 2001 \\
\hline & $\begin{array}{l}\text { Se descarta la idea de la construcción del } \\
\text { puente por sus altos costos económicos }\end{array}$ & $\begin{array}{l}\text { Presidenta Michelle Bachelet } \\
\text { (ler gobierno) }\end{array}$ & 2006 \\
\hline \multirow{4}{*}{$\begin{array}{l}\text { Licitaciones, estudios } \\
\text { y plazos ideales en } \\
\text { torno a la } \\
\text { construcción del } \\
\text { puente. }\end{array}$} & $\begin{array}{l}\text { En el discurso presidencial del } 21 \text { de mayo, } \\
\text { anuncia la licitación de la construcción del } \\
\text { puente }\end{array}$ & $\begin{array}{l}\text { Presidente Sebastián Piñera (ler } \\
\text { gobierno) }\end{array}$ & 2012 \\
\hline & Proyecto puente bicentenario (No cumplido) & $\begin{array}{l}\text { Administración Presidente } \\
\text { Ricardo Lagos }\end{array}$ & $\begin{array}{l}\text { 2002-2006 } \\
\text { (Plazo ideal) }\end{array}$ \\
\hline & $\begin{array}{l}\text { Proyecto de construcción del Puente (No } \\
\text { cumplido) }\end{array}$ & $\begin{array}{l}\text { Presidente Sebastián Piñera (ler } \\
\text { gobierno), Presidenta Michelle } \\
\text { Bachelet (2do gobierno) y } \\
\text { Presidente Sebastián Piñera (2do } \\
\text { gobierno) }\end{array}$ & $\begin{array}{l}2013-2019 \\
\text { (Plazo ideal) }\end{array}$ \\
\hline & $\begin{array}{l}\text { Licitación por las obras de construcción del } \\
\text { puente (Presupuesto de } 740 \text { millones de } \\
\text { dolares) para el diseño inicial }\end{array}$ & $\begin{array}{l}\text { Adjudicada por: las empresas } \\
\text { OAS, Hyundai, Systra y Aas- } \\
\text { Jakobsen }\end{array}$ & 2013 \\
\hline
\end{tabular}




\begin{tabular}{|c|c|c|c|}
\hline \multirow{13}{*}{$\begin{array}{l}\text { "Inicio de la obra de } \\
\text { construcción y } \\
\text { controversia socio- } \\
\text { territorial: La } \\
\text { emergencia y la } \\
\text { reacción de los } \\
\text { habitantes de Chiloé" }\end{array}$} & $\begin{array}{l}\text { Un estudio revela una serie de errores en el } \\
\text { cálculo de la demanda, mostrando que la } \\
\text { factibilidad del puente no se alcanza hasta el } \\
\text { año } 2029\end{array}$ & Navarro. C & 2014 \\
\hline & $\begin{array}{l}\text { Se publican resultados de una encuesta. Solo } \\
\text { un } 4 \% \text { de los habitantes de Chiloe creen que la } \\
\text { construcción del puente es prioritaria }\end{array}$ & $\begin{array}{l}\text { Centro de estudios sociales de } \\
\text { Chiloe (CESCH) }\end{array}$ & 2015 \\
\hline & Se anuncia un nuevo plazo ideal & Ministerio de Obras Publicas & $2017-2020$ \\
\hline & $\begin{array}{l}\text { Acusaciones de corrupción contra la empresa } \\
\text { brasilera OAS. Según la información disponible, } \\
\text { la Corte de Apelaciones de Santiago bloqueó la } \\
\text { participación de OAS en el Consorcio Puente de } \\
\text { Chacao S.A a petición de la empresa Hyundai }\end{array}$ & $\begin{array}{l}\text { Empresa OAS, Empresa } \\
\text { Hyundai, Corte de apelaciones } \\
\text { de Santiago. }\end{array}$ & 2018 \\
\hline & $\begin{array}{l}\text { Comienzo obra instalación pilote prueba en la } \\
\text { roca remolino }\end{array}$ & Hyundai & $\begin{array}{l}\text { Febrero } \\
2018\end{array}$ \\
\hline & $\begin{array}{l}\text { Diversas organizaciones se reúnen en el III } \\
\text { encuentro de redes territoriales (Quellón). }\end{array}$ & $\begin{array}{l}\text { Organizaciones territoriales del } \\
\text { Archipiélago de Chiloe: } \\
\text { agrupación sociocultural Aitué, } \\
\text { consejo de comunidad williche, } \\
\text { colectivo informativo } \\
\text { "mapuexpress y Movimiento } \\
\text { Defendamos Chiloe }\end{array}$ & Marzo 2018 \\
\hline & $\begin{array}{l}\text { Las organizaciones locales exigen: Un estudio } \\
\text { de impacto ambiental, una consulta indígena, } \\
\text { un diálogo ciudadano participativo y de alto } \\
\text { nivel con la comunidad chilota," y que se } \\
\text { esclarezca la participación de OAS en la } \\
\text { ejecución del proyecto }\end{array}$ & $\begin{array}{l}\text { Organizaciones territoriales del } \\
\text { Archipiélago de Chiloe }\end{array}$ & $\begin{array}{l}\text { Marzo-junio } \\
2018\end{array}$ \\
\hline & $\begin{array}{l}\text { La cuestionada empresa brasileña OAS ya no } \\
\text { es parte de la construcción del puente. Hyundai } \\
\text { tiene comprada la participación de OAS } 49 \% \\
\text { de las acciones }\end{array}$ & $\begin{array}{l}\text { Ministro Juan Fontaine } \\
\text { i (Ministerio de Obras Publicas), } \\
\text { OAS y Hyundai }\end{array}$ & Junio 2018 \\
\hline & $\begin{array}{l}\text { Consorcio solicita aumento de tiempo y } \\
\text { recursos, petición rechazada por el MOP }\end{array}$ & Hyundai y MOP & Julio 2018 \\
\hline & $\begin{array}{l}\text { MOP reconsidera la petición y aumenta en } 31 \\
\text { meses el plazo para la construcción del Puente }\end{array}$ & MOP & $\begin{array}{l}\text { Diciembre } \\
2018\end{array}$ \\
\hline & $\begin{array}{l}\text { MOP aprueba el diseño definitivo, se espera la } \\
\text { finalización de la obra el } 2023\end{array}$ & MOP & $\begin{array}{l}\text { Diciembre } \\
2018\end{array}$ \\
\hline & $\begin{array}{l}\text { Se solicita esclarecer los criterios de la } \\
\text { evaluación social del proyecto }\end{array}$ & Organizaciones territoriales & 2018-2019 \\
\hline & $\begin{array}{l}\text { Negociación por aumento del presupuesto, } \\
\text { considerando costos extras en la obra }\end{array}$ & Hyundai y MOP & $2019-2020$ \\
\hline
\end{tabular}

Fuente: Elaboración propia (2020).

\section{Interfaces de actores y miradas}

Si bien hasta el momento no se detecta un estudio empírico de carácter cuantitativo que evidencie el apoyo o rechazo a la construcción del puente, cada postura reclama ser la representante de la mayoría. Lo más medible sobre lo señalado, es una encuesta realizada por el Centro de Estudios Sociales de Chiloé (Henríquez et al., 2015), sobre prioridades territoriales en la Isla.

Ante la pregunta: ¿Cuál cree usted que es la necesidad más urgente para cubrir en el archipiélago Chiloé?, el puente aparece con un bajo nivel de apoyo cercano al 4,24\%, lejos del 65\% que obtiene la construcción de un hospital de alta complejidad con especialistas (Henríquez et al., 2015). 
Desde la mirada institucional (Figura 1) los recursos para construir el puente están justificados técnicamente y son necesarios para lograr la conectividad de la isla con el continente, con todos los objetivos de desarrollo e integración territorial vinculados (Figueroa \& Rozas, 2005), además de estar legitimado al ser un anhelo de los mismos chilotes (MOP, 2012), el análisis de las posturas críticas muestra efectos contradictorios. Por un lado, se encuentra el efecto aislación que provocaría el puente para estas dos localidades. Esto, que podría sonar paradójico en un proyecto que se fundamenta en la noción de conectividad, se explica porque el emplazamiento físico de las futuras obras se realizará fuera del circuito actual que sigue la ruta 5 y que incluye a Pargua y Chacao como parte de la ruta entre la isla y el continente (Anabalon, 2018).

Si bien las organizaciones locales tienden a rechazar el proyecto de la construcción, existe el comité propuente que avala la iniciativa, es decir, estamos ante una pluralidad de actores en desacuerdo. Esto también revela que la construcción de un universo compartido es acompañada a menudo por el choque de mundos en conflicto.

Uno de los hechos fundamentales de esta controversia, y que no habría sido posible sin la intervención de las organizaciones locales, fue la expulsión de la empresa OAS como ejecutora de la obra. La resistencia y contra experticia de las organizaciones locales provocó que se revisara el proceso de evaluación del impacto social del proyecto en relación con los actores y consorcios (Figura 2).

Entre marzo y junio del 2018, las organizaciones locales se reunieron para exigir un estudio de impacto ambiental, una consulta indígena, un diálogo ciudadano participativo y de alto nivel con la comunidad chilota, y que se esclarezca la participación de OAS en la ejecución del proyecto. Esto tuvo como resultado que las múltiples acusaciones de corrupción contra la empresa brasilera OAS derivaran en que la Corte de Apelaciones de Santiago bloqueara la participación de OAS en el Consorcio Puente de Chacao S.A. a petición de la empresa Hyundai y de las organizaciones locales. Igualmente, la presión de las organizaciones locales (Figura 3) que contaron con la venia de la Contraloría General de la Republica, quienes avalaron revisar la evaluación social del proyecto, también influyeron en que el Ministerio de Obras Públicas decidiera "no aprobar" la petición del consorcio (que actualmente es solo Hyundai, véase línea de tiempo 2) de aumentar el plazo y los recursos para la petición del puente.

Esperamos que esta denuncia, que ya fue acogida por la Fiscal, logre acreditar que todo el proceso del puente Chacao está viciado y que se ponga fin al contrato, exigiendo las garantías que corresponde, de modo que si es que se ejecuta el proyecto sea de manera legal y luego de haber resuelto las prioridades reales de los habitantes de Chiloé (Dirigente Agrupación sociocultural AYTUE, 2019 apud La Tercera, 2019). 


\section{Cartografía de actores 1: Actores institucionales²}

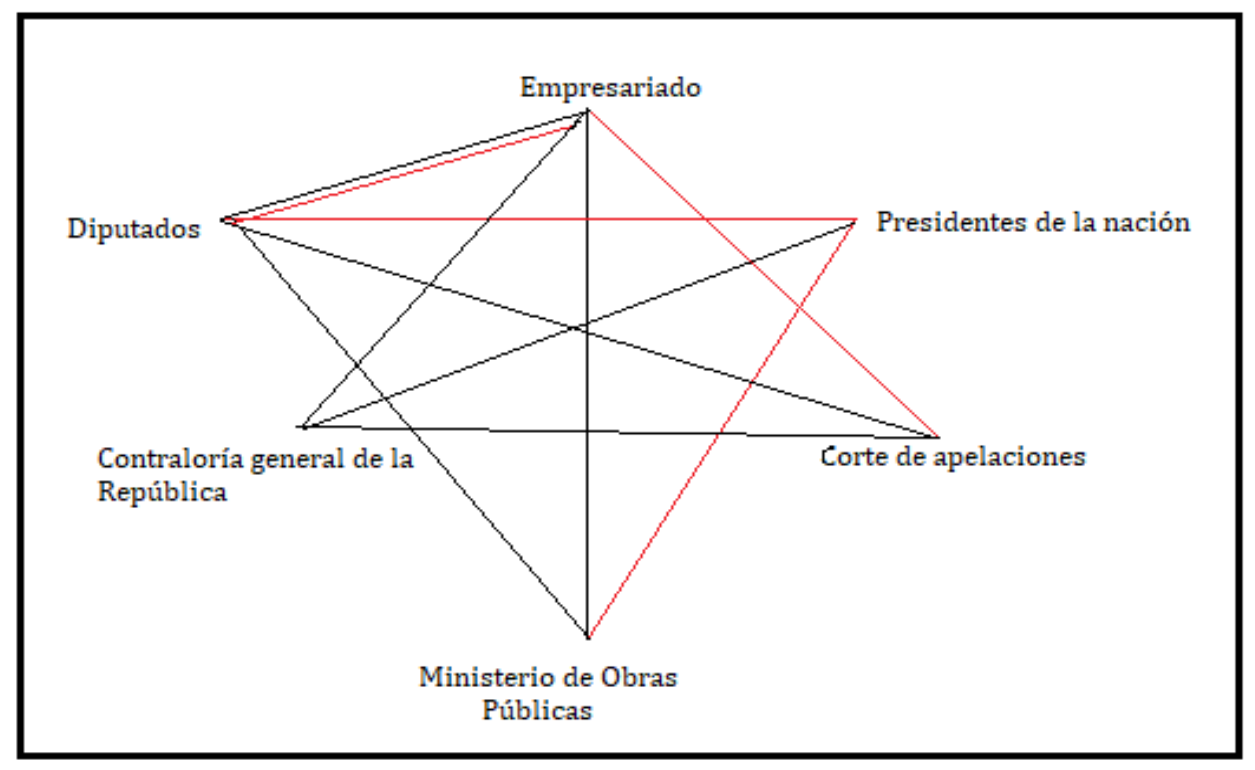

Figura 1 - Cartografía de actores. Fuente: elaboración propia (2020).

En la cartografía 1 observamos la relación entre los diversos actores involucrados en la problemática, donde la acción de uno de estos provoca la reacción del resto, generando una cadena de diversas actividades que implican controversias en base a la infraestructura de la movilidad. En este sentido, los intereses opuestos entre los diversos actores provocan una infinidad de reacciones, donde identificamos la institucionalidad como agente determinante en la producción de controversias. Asimismo, existe una construcción de vigilancia mutua entre las diversas instituciones implicadas en la temática, que permea todas las esferas a nivel de toma de decisiones de carácter político. La desconfianza sobre el futuro de la ejecución de este proyecto revela una "incertidumbre compartida" propia de las controversias (Venturini, 2009), en donde ninguna de las partes involucradas parece estar segura acerca del devenir de esta mega-obra.

Es importante enfatizar que fueron estos actores institucionales quienes definieron el progreso de la Isla en función de esta opción de conectividad, lo que generó una respuesta por parte de un sector de la comunidad local que invoca, no solamente que no se les consultó si querían un puente, sino que también no se barajaron otras opciones de movilidad.

Debió haberse realizado un estudio comparativo de alternativas de conexión entre Chiloé y Chile continental, entre las opciones de túnel, puente, transbordadores y otro medio de navegación, y luego haber efectuado la ingeniería de detalle de la alternativa más conveniente en lo económico, social y técnico (Habitante de Chiloé 2019. apud La Tercera, 2019).

\footnotetext{
2 En rojo las controversias y en negro los acuerdos.
} 


\section{Cartografía de actores 2: Actores consorcio internacional (o privados) ${ }^{3}$}

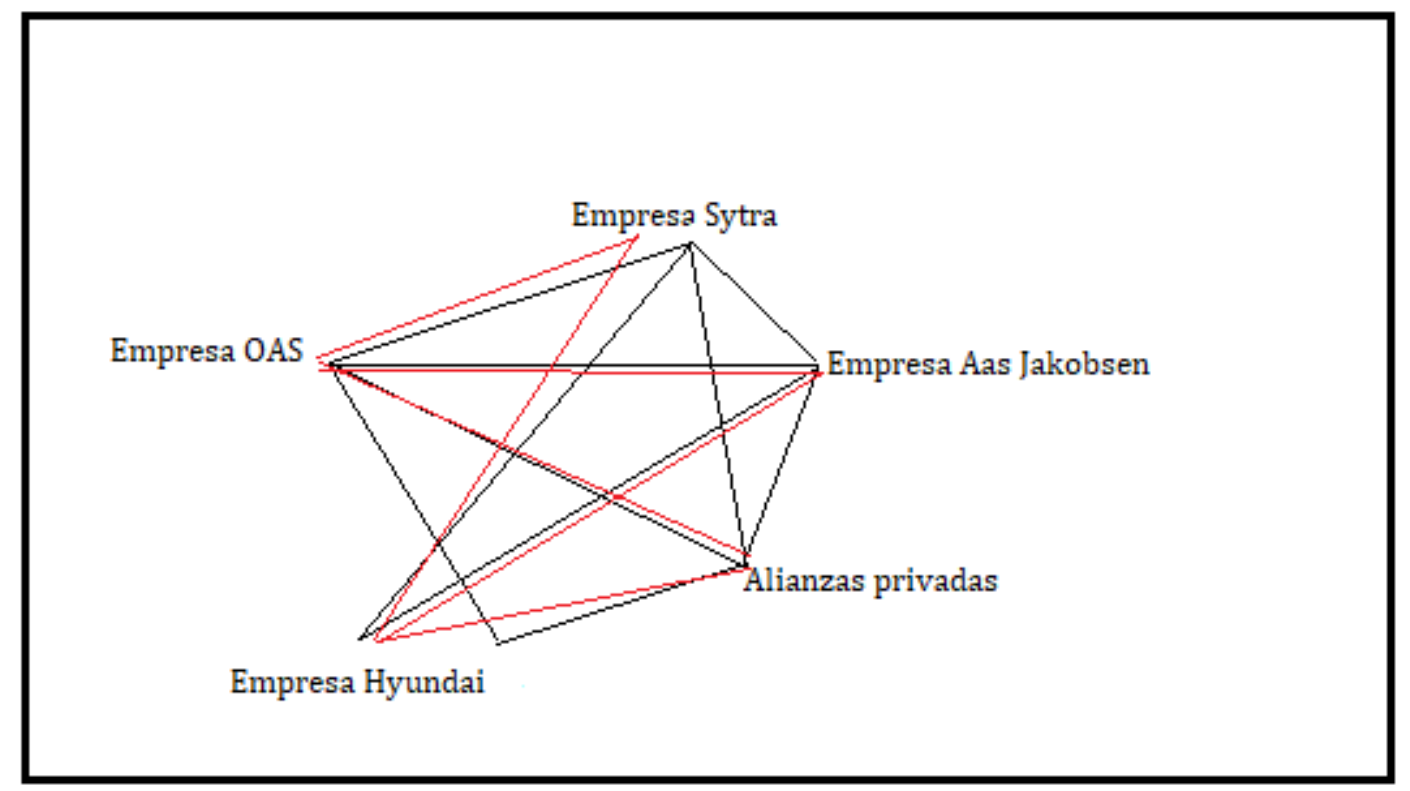

Figura 2. Actores internacionales o privados Fuente: elaboración propia (2020).

Respecto a la cartografía 2, señalamos la existencia de intereses económicos que provocan rupturas vinculadas al desarrollo de la infraestructura de la movilidad. El puente, como objeto de deseo en tensión, involucra la emergencia de diversos grupos económicos internacionales que se interesan en ejecutar el proyecto, lo cual ha generado múltiples inconvenientes que hasta el día de hoy han resultado imposibles de solucionar. El poder económico implica constantes controversias en los territorios, provocando la aparición de agentes que observan los movimientos de la economía y su impacto en el desarrollo de la infraestructura de la movilidad. Evidencia de lo anterior son las denuncias mutuas que realizaron las empresas Hyundai y OAS para quedarse de manera exclusiva con la licitación del proyecto.

Como ya lo hemos establecido, la empresa OAS fue cuestionada por los propios habitantes de Chiloé, quienes interpusieron denuncias formales.

OAS aquí en Chiloé nunca se estableció como empresa, nunca vimos a nadie de OAS físicamente, era como una empresa de papel (Denunciantes locales, 2019 apud la Tercera, 2019).

\footnotetext{
3 En rojo las controversias y en negro los acuerdos.
} 


\section{Cartografía de actores 3: Organizaciones locales}

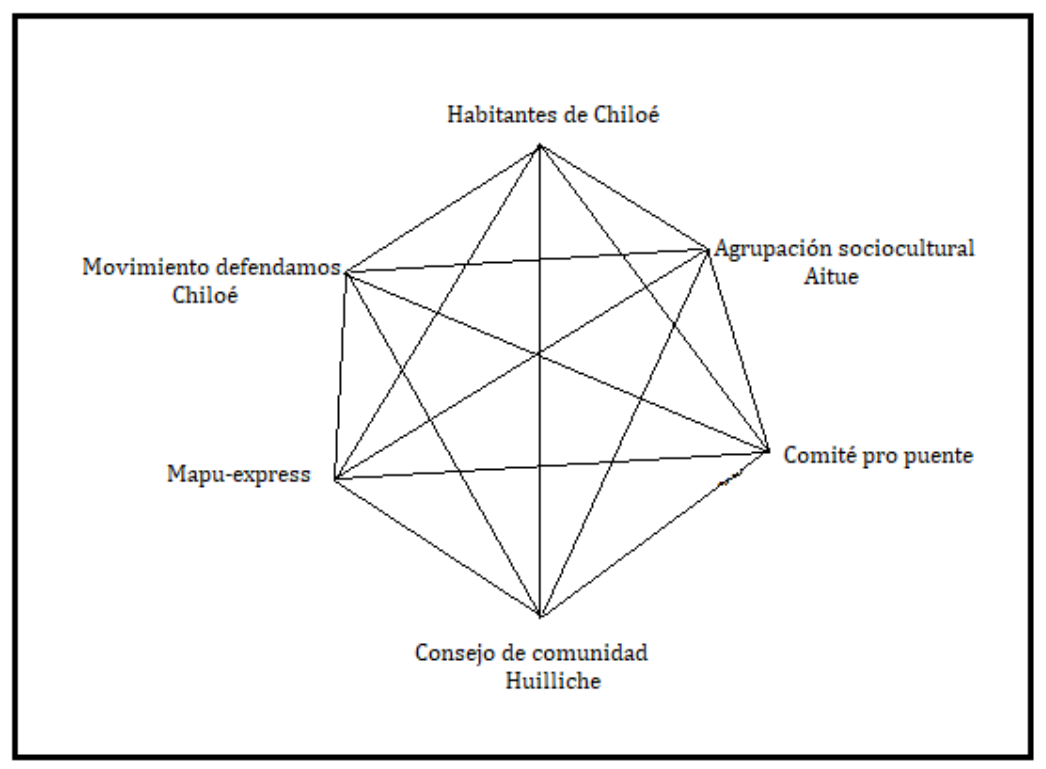

Figura 3. Actores locales. Fuente: Elaboración propia (2020).

En relación con la cartografía de actores 3, identificamos la existencia de organizaciones locales que han planteado pros y contras en la ejecución del puente, evidenciado impactos negativos y positivos con su arribo. En este sentido, asoman demandas centrales por parte de estos actores como estudio de impacto ambiental, consulta indígena, nivel de participación de OAS en el proyecto e inicio de un diálogo ciudadano. Todas estas peticiones reabren controversias respecto a la relación con la cartografía 1 y cartografía 2, generando una hiper cartografía de actores e instituciones involucrados en la temática.

Uno de los elementos interesantes a considerar es que, en una controversia, dentro de un mismo grupo de interés, pueden existir posturas disimiles. Ya hemos comentado acerca de voces a favor y en contra de la construcción del puente. Un reportaje del diario "The Clinic" en enero del 2020, recopiló diversos testimonios de "actores locales" y sus percepciones sobre el futuro puente. Destacamos algunos enunciados:

No me gusta el famoso puente, porque Chiloé es una isla. Hay que cuidar la isla tal como es por dentro y no darla a conocer tan a la luz porque van a llegar más empresas, claro, son más empleos, pero en Chiloé falta crecimiento interno (Habitante de Chiloé, 2020 apud The Clinic, 2020).

Tienen que hacer ese puente, sí o sí. Sería conveniente para todos, es más rápido por ejemplo para las ambulancias cuando hay algún accidente (Habitante de Chiloé, 2020 apud The Clinic, 2020).

Probablemente el punto más álgido de la controversia guarda relación con una propuesta de conectividad/movilidad impuesta por el Estado y ejecutada por una empresa privada, a través de licitaciones y procesos que han sido cuestionados y denunciados, que no representa los verdaderos intereses de la comunidad local de Chiloé. Además, existen otras irregularidades asociadas al proyecto, como la falta de un proceso de participación ciudadana y de una consulta indígena.

En una declaración pública del año 2017 las organizaciones locales proponen:

Re-asignar estos dineros públicos MOP para que sean utilizados en obras públicas de la misma cartera y que históricamente han sido postergadas para el pueblo chilote, que otorguen mayor conectividad interna: marítima, terrestre y área, inversión urgente en agua potable rural y otras como hospital base para Chiloé y campus universitario y centro de formación técnica estatal, además de rampas de doble 
frente de atraque en el canal de Chacao, para acelerar la carga y descarga de transbordadores (Defendamos Chiloé y otras organizaciones ambientales e indígenas, 2017 apud La izquierda diario, 2017).

En esta línea, para el Estado, definido por la relevancia del gobierno de Chile en Chiloé, esta inversión significa un avance hacia la conectividad e integración, pero para las personas que habitan el territorio de Chiloé "es un despilfarro de fondos públicos". El llamado a invertir en obras postergadas y prioritarias para los chilotes, en lugar de privilegiar la construcción de un puente de unión continental, evidencia que conlleva considerar que para las personas es importante preservar la identidad insular de un territorio con particularidades geográficas pero también idiosincráticas.

Cada una de las tres figuras presentadas implica pensar la relación entre controversias y su desarrollo histórico vinculado al proyecte puente de Chacao. Al observar a través de las cartografías presentadas el cause particular entre los grupos de actores involucrados en diferentes niveles de la problemática, más que identificar causas y efectos, se abren diversas entradas metodológicas para analizar las disímiles apreciaciones respecto a un mismo hecho. Así, las controversias conforman una entrada para la movilidad y los actores involucrados en un espiral de relaciones y sectores sociales. Adicionalmente, los discursos presentados que descubren las posiciones antagónicas de los actores involucrados nos invitan a pensar que la controversia parece no estar en una etapa de disolución, y que los interesados aun no logran "ponerse de acuerdo en su desacuerdo" (Latour, 2002).

Si bien, los actores involucrados han asumido que no pueden ignorarse (Latour, 2002, Venturini, 2009), ninguna de las posturas ha podido extender lo suficiente sus redes para persuadir a los demás involucrados y lograr un acuerdo. El proyecto ya está en plena ejecución, lo que supone un triunfo para la única empresa que se adjudicó los recursos de la licitación, además, esta fue capaz de presionar al Estado para conseguir más recursos de los pactados inicialmente. El Estado sigue firme en su idea de que el proyecto garantiza conexión, velocidad e integración para los habitantes de Chiloé.

La premisa de Latour (2002) respecto a que son los "más informados" quienes mantienen viva una controversia a través de argumentos plausibles para oponerse a aquello que se les está imponiendo, cobra vigencia en esta controversia. Para este caso, considerando que las voces del desacuerdo estuvieron representadas por asambleas territoriales, agrupaciones socioculturales y grupos étnicos, se puede establecer que quienes disputan los espacios discursivos y políticos no solo son los más informados, sino también los "más organizados", aquellos grupos que se articulan en función de retoricas "localmente atractivas", sobre todo de discursos que apelan a la defensa de la identidad territorial.

\section{Conclusiones}

El presente trabajo permitió abrir la discusión respecto a cierta tendencia por sacralizar lugares y tensionar la llegada del progreso y la civilización, como procesos sociales que irrumpen en la cultura local y sus respectivas prácticas cotidianas. La movilidad juega un papel fundamental en la transformación de las costumbres y tradiciones de los isleños, poniendo al puente como objeto interurbano que responde a las manifestaciones del paradigma de la movilidad. Así, las controversias operan en territorios que hasta no mucho tiempo eran observados como secundarios en el crecimiento económico del país, tornándose una figura que hipotéticamente tributará al desarrollo social de los ciudadanos, lo cual aún es fuente de polémica. Lo que se debate trasciende las discusiones técnicas acerca de la viabilidad de un proyecto de instalación de infraestructura, emergiendo una controversia entre las diversas visiones de mundo, donde, por un lado, un Estado centralista impone un proyecto de pretensiones modernizadoras, so pretexto, que esta iniciativa garantiza la conectividad e integración territorial de un archipiélago históricamente aislado. Por otro lado, 
pareciera que un gran número de la población local está en contra del proyecto, en donde destacan algunos argumentos como, por ejemplo, que el Estado podría invertir más recursos en otras obras prioritarias, como la construcción de un Hospital y mejorar los caminos interiores de las islas. El tercer actor involucrado fue el sector privado, en un primer momento fueron varias empresas que entraron en el diseño y ejecución del proyecto, y que finalmente una sola terminó monopolizando la obra.

Consideramos que la perspectiva de las controversias aporta considerablemente en la revisión, diagnóstico, seguimiento y comprobación de situaciones sociales propicias para el estudio de la movilidad. Por un lado, la revisión que realizamos de algunos hitos trascendentales en lo que respecta al puente, como objeto urbano propio de la infraestructura de la movilidad, abre diversas entradas para observar y analizar su impacto en la sociedad isleña. Por otro lado, ciertos actores, discursos y prácticas fueron identificadas como promotoras de la implementación y detención del puente, respondiendo a discursos políticos y culturales que conflictúan con agentes opuestos, que observan el puente como catalizador de nuevas problemáticas sociales.

En nuestro caso, el estudio del puente se torna representativo de un proyecto político vinculado a la infraestructura de la movilidad, que a pesar del tiempo sigue siendo un caso altamente representativo de controversias. Transformaciones sociales, implicancias económicas y rasgos culturales, constituyen ejes centrales en la comprensión del habitar isleño, donde el puente deja de ser un simple objeto interurbano para representar pautas de dominación, asimilación y reestructuración social. De esta forma, tal como se evidenció en las páginas anteriores, la movilidad está impregnada de controversias, lo cual enriquece la virtud paradigmática de esta categoría de análisis.

Asimismo, sostenemos que la versatilidad entregada por el concepto controversias para observar la problemática en cuestión nutre y, de algún modo, supera ciertos aportes de la teoría del conflicto, considerado como situación constitutiva de sociedades como las nuestras, las cuales se caracterizan por la convivencia de múltiples grupos sociales que cohabitan en un mismo espacio-tiempo y sostienen intereses económicos, políticos y culturales diversos.

Finalmente, creemos necesario expandir las reflexiones aquí presentadas una vez se haya plasmado la ejecución de la infraestructura en cuestión, no obstante, avanzar en el seguimiento de las controversias que este medio trae consigo permitirá recabar información necesaria para incluir a todas y todos los actores sociales involucrados. Sugerimos continuar desarrollando investigaciones en esta incipiente área, especialmente aquellas que incorporen la percepción de personas mayores, jóvenes, mujeres, hombres y niños que viven en la isla y que son actores fundamentales en la controversia de la movilidad aquí expuesta.

\section{Referencias}

Amín, A., \& Thrift, N. (2004). The "emancipatory" city? L. Lees (Ed.), The emancipatory city? Paradoxes and possibilities (p. 231235). Sage: London.

Anabalon, P. (2018). Movilidades costeras, desigualdad y exclusión territorial: Practicas de movilidad en Chiloé. LIDER, 20(33), 67-94.

Augé, M. (2007). Por una antropología de la movilidad. Barcelona: Gedisa.

Augé, M. (2000). Los no lugares. Espacios del anonimato. Una antropología de la sobremodernidad. Barcelona: Gedisa.

Bauman, Z. (2003). La modernidad liquida. México: Fondo de Cultura Económica.

Bijker, W. E., \& Pinch, T. J. (1987). The social construction of facts and artifacts: or how the sociology of science and the sociology of technology might benefit each other. In W. E. Bijker, T. P. Hughes, \& T. Pinch (Eds.), The social construction of technological systems: New Directions in the Sociology and History of Technology (p. 399-441). Cambridge, Massachusetts: The MIT Press. 
Bravo, J. (2004). La cultura chilota y su expresión territorial en el contexto de la globalización de la economía (tesis de grado). Facultad de Arquitectura y Urbanismo, Universidad de Chile. Recuperado el 2 de noviembre del 2019, de http://www.repositorio.uchile.cl/handle/2250/100580.

Buschmann, A., \& Jacob, D. (2013). Arqueología de una controversia: El Centro Industrial de Ventanas. Recuperado el 15 de noviembre del 2019, de https://www.nomascarbon.cl/wp-content/uploads/2015/08/arqueologiaquintero.pdf.

Callon, M. (1986). Some Elements of a Sociology of Translation: Domestication of the Scallops and the Sishermen of St. Brieuc Bay. In J. Law (Ed.), Power, Action and Belief: A New Sociology of Knowledge (p. 196-233). London: Routledge.

Callon, M. (1995). Technological conception and adoption network: Lessons for the Cina 16. TA practitioner. In A. Rip, T. J. Misa, \& J. Schot (Eds.), Managing technology in society: The approach of constructive technology assessment (p. 307-330). London: Pinter.

Callon, M., Lascoumes, P., \& Barthe, Y. (2001). Agir dans un monde incertain: essai sur la démocratie technique. Paris: Seuil.

Calonge, F. (2014). Movilidades capitalistas e identidades subalternas. Te mueves porque te mueven. Sociológica, 29(83), 129164.

Chateauraynaud, F., \& Torny, D. (1999). Les Sombres Précurseurs. Paris: MSH.

Cresswell, T. (2010). Towards a politics of mobility. Environment and planning D: society and space, 28 (1), 17-31. https://doi.org/10.1068/d11407

Dahrendorf, R. (2007). The Modern Social Conflict: The Politics of Liberty. United Kingdom: Taylor \& Francis Inc.

Dahrendorf, R. (1959). Class and class conflict in industrial society. Stanford: Stanford University Press (1ra edición).

Dahrendorf, R. (1971). Sociedad y Libertad. Madrid: Tecnos.

El Mostrador Diario digital (2012). "Piñera intenta aislar descontento con bono por alimentos y anuncia puente para Chiloé". Discurso presidencial del 21 de mayo del 2012. Valparaíso (Chile). Recuperado el 1 de septiembre del 2020, de https://www.elmostrador.cl/noticias/pais/2012/05/21/pinera-intenta-aislar-descontento-con-bono-por-alimentos-yanuncia-puente-para-chiloe/

Figueroa, O., \& Rozas, P. (2005). Conectividad, ámbitos de impacto y desarrollo territorial: el caso de Chile. Santiago de Chile: Comisión Económica para América Latina y el Caribe (CEPAL). 84 p.

Giddens, A. (1993). Consecuencias de la modernidad. Madrid: Alianza Editorial.

Henríquez, C., Navarro, J., Mariñanco, A., \& Mondaca, E. (2015). Primera Encuesta Provincial en Chiloé y sus prioridades. Centro de Estadios sociales de Chiloé (CESCH). Recuperado el 1 de septiembre del 2020, de http://docs.wixstatic.com/ugd/3f1b41_9dcd8bc9f8b347c3a6fdb8e1aa83b938.pdf

Hughes, T. (1987). The evolution of large technological systems. In W. E. Bijker, T. P. Hughes, \& T. Pinch (Eds.), The social construction of technological systems. New directions in the sociology and history of technology (pp. 51-82). Cambridge, Massachusetts: The MIT Press.

Ingold, T. (2004). Culture on the ground the world perceived through the feet. Journal of material culture, 9(3), 315-340. https://doi.org/10.1177/1359183504046896.

Jolivet, E., \& Heiskanen, E. (2010). Blowing Against the wind-An exploratory application of actor network theory to the analysis of local controversies and participation processes in wind energy. Energy Policy, 8, 6746-6754.

https://doi.org/10.1016/j.enpol.2010.06.044

Landström, C., \& Whatmore, S. (2011). Flood Apprentices: an exercise in making things public. Economy and Society, 40 (4), 1-29. https://doi.org/10.1080/03085147.2011.602540

Lange Valdés, C. (2011). Dimensiones culturales de la movilidad urbana. Revista INVI, 26(71), 87-106.

La Izquierda Diario (2017). “Organizaciones de Chiloé vuelven a rechazar Puente Canal de Chacao”, 12 de diciembre del 2017. Chiloe, Chile. Recuperado el 1 de septiembre del 2020, de http://www.laizquierdadiario.cl/Organizaciones-de-Chiloe-vuelvena-rechazar-Puente-Canal-de-Chacao 
La Tercera (2019). "Dirigentes de organizaciones sociales de Chiloé declararon ante la PDI por denuncias sobre Puente Chacao" 26 de septiembre del 2019. Chiloe, Chile. Recuperado el 1 de septiembre del 2020, de

https://www.latercera.com/nacional/noticia/nunca-vimos-nadie-oas-una-empresa-papel-dirigentes-organizaciones-socialeschiloe-declararon-ante-la-pdi-denuncias-puente-chacao/836327/

Latour, B., \& Hermant, E. (1998). Paris ville invisible. Paris: La Découverte-Les Empêcheurs de penser en rond. Traducción al inglés por Liz Carey-Libbrecht (2006). Recuperado el 20 de noviembre del 2019 de

http://www.brunolatour.fr/sites/default/files/downloads/viii_paris-city-gb.pdf

Latour, B. (1987). Science in Action: How to Follow Scientists and Engineers through Society. Cambridge: Harvard University Press.

Latour, B. (1989). Pasteur et Pouchet: hétérogenèse de l'histoire des sciences. In M. Serres (dir.), Eléments d'histoire des sciences (p. 423-445). Bordas: Paris. Recuperado el 20 de noviembre del 2019, de http://www.brunolatour.fr/sites/default/files/38-POUCHET-FR.pdf

Latour, B. (1992). Where are the Missing Masses? Sociology of a Few Mundane Artefacts. In W. E. Bijker, \& J. Law (Eds.), Shaping Technology - Building Society. Studies in Sociotechnical Change (p. 225-259). Cambridge, MA: MIT Press.

Latour, B. (2002). Morality and technology: The end of the means. Theory, Culture \& Society, 19(5), 247-260.

https://doi.org/10.1177/026327602761899246.

Latour, B. (2004). Politics of Nature. Cambridge, Massachusetts: Harvard University Press.

Latour, B. (2005). Reassembling the Social: An Introduction to Actor-networks-theory. Oxford: Oxford University Press.

Latour, B. (2007). La cartographie des controversies. Technology Review, 82-83.

Lefebvre, H. (2013). La producción del espacio. Madrid: Capitán Swing.

Ministerio de Obras Públicas - MOP (2012). Proyecto Puente Chacao: Resumen Ejecutivo. Chiloe, Chile. Recuperado el 30 de octubre del 2019, de http://www.mop.cl/puentechiloe/Documents/Resumen\%20Puente\%20Chacao.pdf

Navarro, C. (2014). Puente de Chacao, ¿rentabilidad política o económica (tesis de maestría). Escuela de economía y negocios, Universidad de Chile. Recuperado el 31 de octubre del 2019, de

http://repositorio.uchile.cl/bitstream/handle/2250/117335/Navarro\%20Gonz\%C3\%A1lez\%20Claudio.pdf

Riquelme, H., López, S., Riquelme, M., \& Meza, N. (2020). Condiciones y ambiente laboral de trabajadoras y trabajadores del retail de La Araucanía. Izquierdas, 49, 1804-1829.

Salazar, N. (2018). Momentous mobilities: Anthropological Musing on the Meanings of Travel. New York: Berghahn Books.

The Clinic (versión digital) (2020). El puente Chacao: una historia con muchas voces. 22 de enero del 2020. Chiloe, Chile. Recuperado el 2 de septiembre del 2020, de https://www.theclinic.cl/2020/01/22/el-puente-chacao-una-historia-conmuchas-voces/

Thrift, N. (2004). Driving in the City. Theory, Culture \& Society, 21(4-5), 41-59. https://doi.org/10.1177/0263276404046060

Thrift, N. (2007). Non-Representational Theory: Space, politics, affect. London: Routledge.

Tironi, M. (2011). Construyendo infraestructuras para la movilidad: el caso del sistema de bicicletas en libre servicio de París. Athenea Digital, 11(1), 41-62. https://doi.org/10.5565/rev/athenead/v11n1.824.

Vannini, P. (2011). Constellations of (in) convenience: disentangling the assemblages of Canada's west coast island mobilities. Social \& Cultural Geography, 12(5), 471-492. https://doi.org/10.1080/14649365.2011.588803.

Vannini, P. (2015). Non-Representational Research Methodologie [en línea]. London: Routledge. Recuperado el 29 de octubre del 2019, de http://www.academia.edu/5217885/NonrepresentationalTheory_and_Methodologies_Re-envisioning.

Venturini, T. (2009). Buceando en el magma. Cómo explorar controversias con la teoría del actor-red. Recuperado el 28 de octubre Del 2019, de

https://www.academia.edu/28748554/Buceando_en_el_Magma_C\%C3\%B3mo_explorar_controversias_con_la_teor\%CC3\%ADa_ del_Actor_Red_Versi\%C3\%B3n_provisional_a_aparecer_en_Comprensi\%C3\%B3n_P\%C3\%BAblica_de_la_Ciencia 
Controversias de la movilidad

Urry, J. (2000). Sociology beyond societies: mobilities for the twenty-first century. London: Routledge.

Zetin-Rodríguez, M. C. (2016). La controversia ambiental en torno a la presa de La Zacatecana, Guadalupe, Zacatecas. Desacatos, (51), 160-179. Recuperado en 13 de diciembre de 2020, de

http://www.scielo.org.mx/scielo.php?script=sci_arttext\&pid=S1607-050X2016000200160\&lng=es\&tlng=.

Editor responsable: Fábio Duarte

Recibido: 12 may. 2020

Aprobado: 01 nov. 2020 